\title{
¿ES REALISTA LA TEORÍA DE LA ARGUMENTACIÓN JURÍDICA? ACOTACIONES BREVES A UN DEBATE INTENSO *
}

\author{
Juan Antonio García Amado \\ Universidad de León
}

RESUMEN. Al hilo del debate entre E. HABA y M. ATIENZA, se trata de resituar y justificar la distinción entre teoría descriptiva y teoría normativa de la argumentación, resaltando la utilidad de elaborar patrones ideales de racionalidad argumentativa con los que medir aproximativamente la racionalidad de las argumentaciones reales. Seguidamente, se mantiene la tesis de que la teoría estándar de la argumentación jurídica no ha rendido muchos instrumentos útiles para el análisis argumentativo de sentencias porque se ha dado la mano con un iusmoralismo cercano a las teorías de la única respuesta correcta y que ve en la argumentación la vía para el descubrimiento de tal respuesta, en lugar de una herramienta para la justificación razonable de elecciones discrecionales bajo condiciones de inevitable incertidumbre.

Palabras clave: argumentación jurídica, E. P. HABA, M. AtienZA, Ó. SARLO.

ABSTRACT. In order to continue the debate between E. HABA and M. ATIENZA, what is necessary is to reposition and justify the distinction between a descriptive theory and a normative theory of argumentation, underlining the usefulness of making ideal patterns of argumentative rationality with which to roughly measure the rationality of real argumentation. After this, the thesis is held that the standard theory of legal argumentation has not provided many instruments useful for the argumentative analysis of decisions because it comes together with a legal moralism which is close to the theories of the only correct answer, and which sees argumentation as the route to the discovery of such an answer, as opposed to a tool for the reasonable justification of discretionary choices under conditions of unavoidable uncertainty.

Keywords: legal argumentation, E. P. HABA, M. AtIenZA, Ó. SaRlo.

* Fecha de recepción: 9 de mayo de 2011. Fecha de aceptación: 13 de mayo de 2011. 
os dos admirados colegas y queridos amigos que polemizan, E. P. HABA y M. ATIENZA, me solicitan una especie de arbitraje con el que dejar aquí zanjados — que no resueltos- sus desacuerdos teóricos. Les agradezco la confianza que el encargo demuestra, aun cuando me pese la responsabilidad que supone. Sea como sea, no me considero ni llamado a poner paz, puesto que guerra propiamente no hay, sino sanísimo debate, ni a dictaminar de qué parte está la razón o está en medida mayor, pues quién sabe si tal fallo, si fuera capaz de darlo, lo podría argumentar racionalmente. Como también estoy llamado a ser breve, y excluido queda que me extienda en mi propia versión del caso y las soluciones posibles, entro al trapo sin más preámbulos, opino sobre lo que en los escritos de HABA (en adelante E. H.) y ATIENZA (en adelante M. A.) he entendido y expongo lo que me han sugerido, teniendo bien en cuenta igualmente la valiosa aportación de otro apreciado colega, Ó. SARLO. También en aras de la brevedad, doy por conocidos por los textos anteriores de cada interviniente y no me entretendré en resumirlos.

1. Es parte fundamental de las tesis «realistas» de E. H. sobre la argumentación judicial la insistencia en los factores de todo tipo (ideológicos, gremiales, culturales, profesionales, circunstanciales, políticos...) que de hecho pueden y suelen determinar las decisiones de los jueces. En lo que sean los jueces conscientes de la influencia de tales factores empíricos y circunstanciales sobre sus decisiones, se verán impelidos y hasta compelidos a ocultar dicha incidencia en sus personales motivos, y en la sentencia ese ocultamiento lo llevarán a cabo disfrazando los mismos de muy objetivas y profesionales razones.

Ya el realismo jurídico de antaño nos había contado que cuantos más métodos le demos al juez, con ánimo normativo, para encauzar su razonamiento hacia la decisión correcta, tanto más ampliamos su libertad decisoria y mayor campo ofrecemos para que sus personales motivos imperen a sus anchas, pues de entre dichos métodos (v. gr. los distintos cánones de la interpretación que la metodología normativa de la interpretación ofrece) escogerá el juzgador en cada ocasión aquellos que mejor le sirvan para disfrazar su opción subjetiva de determinación objetiva por el Derecho y la razón jurídica. Más recientemente, unos cuantos autores del movimiento Critical Legal Studies, tan bien expuesto aquí hace años por J. A. PÉREz LLEDó, resaltaron la fuerza con que los intereses políticos y corporativos del juez y su afán por hacer carrera dirigen tan a menudo su «política» decisoria, la estrategia que subyace a sus sentencias.

Lo que E. H. subraya es que el tipo de «racionalidad» que en las sentencias se hará patente es el mismo que con carácter general impera entre los juristas, sean prácticos, dogmáticos o iusfilósofos, ideología llena de mitos, mistificaciones, idealismos más o menos ingenuos y manipulaciones, empezando por todo tipo de artificios semánticos y por la fe en más que problemáticas y fantasmagóricas nociones, como naturalezas jurídicas, naturalezas de las cosas, justicias objetivas y dignidades sustanciales; es decir, lo que E. H. describe bajo la etiqueta, quizá no muy afortunada, de «síndrome normativista» y que a otros quizá nos gustaría más denominar ideología gremial dominante entre juristas.

Verdad es, o parece, que disciplinas jurídicas enteras quedarían poco menos que al desnudo y sin referencias si tuvieran que explicar su objeto sin esencialismos metafísi- 
cos, sin realismos conceptuales descaradamente inanes y sin la obsesiva convicción de que si la realidad empírica y la praxis corriente no se adecuan a los árboles genealógicos de conceptos, a las esencias definitorias, a las naturalezas jurídicas y a los dogmas que ya sentaron hasta el fin de los tiempos ULPIANO y GAYO, peor para la realidad y para la praxis y bastará con no ocuparse de ellas y seguir explicando tal o cual materia desde el puro cielo de los conceptos, mera jurisprudencia en broma pero que se piensa seria y no se sabe risible y, más que nada, inútil, en el mejor de los casos.

La acusación principalísima que E. H. formula contra la teoría «estándar» de la argumentación jurídica, representada por autores de la talla de ALEXY o ATIENZA, es que no sólo prescinde de cualquier visión «realista» de la argumentación de los jueces, del modo como de hecho los jueces argumentan y de cómo de hecho pueden argumentar, al estar sometidos a todo tipo de determinaciones ideológicas, prácticas, políticas y hasta laborales, sino que, además, oculta tal realidad mediante crudas idealizaciones. En suma, que tal teoría de la argumentación reemplaza la realidad por el ideal y acaba presentando el ideal como si fuera real. Al final, y por causa de ese desplazamiento de la perspectiva, ya no vemos al juez de carne y hueso, sino al juez Hércules (permítaseme expresarlo así, de mi cosecha) y ya no examinamos la argumentación de las sentencias que están en el papel, sino la hipotética de aquellas que a lo mejor se dictarían si esto fuera una comunidad ideal de diálogo, la comunión de los santos o una comunidad «hercúlea».

2. Uno de los ejes de este debate se halla en la distinción entre lo descriptivo y lo normativo. Parece que E. H. presenta las teorías normativas de la argumentación judicial como teorías que evitan o, incluso, suplantan las descripciones de dicha argumentación, las teorías descriptivas de tal argumentación de los jueces. Por esa vía acontecería la idealización perniciosa que tanto preocupa a E. H., por la vía de dejar de hablar de cómo los jueces de hecho argumentan y de por qué lo hacen así, para referirse nada más que al modo como argumentarían si fuesen ellos perfectamente racionales y su situación social y profesional les permitiera mostrarse así en sus sentencias.

Dos comentarios importa hacer en este punto esencial de la discusión. El primero para restablecer la diferencia entre teorías normativas y teorías descriptivas y resituar la función de unas y otras en la teoría jurídica. El segundo para analizar si hay algo de razón en la acusación de E. H. de que la teoría estándar de la argumentación idealiza y oculta al juez real y sus circunstancias y, de ser así, para preguntarse por qué habría ocurrido tan paradójico efecto.

2.1. Comencemos con una comparación y esperemos que sea pertinente a los efectos que ahora importan. Algún médico o profesor de medicina podría escribir un tratado de la perfecta salud. En él se irían enumerando los parámetros de perfecto estado y perfecto funcionamiento de cada parte del cuerpo humano o, incluso, de cada órgano. ¿Tendría sentido una obra tal? Por qué no. Al fin y al cabo, la enfermedad o la dolencia corporal no es más que la deficiencia de alguno de esos parámetros de salud perfecta. Ante un tratado así, podría algún E. HABA afirmar, con perfecto criterio, que no existe el individuo humano totalmente sano y que todos cojeamos de algún pie, o de los dos. Basta hacerse revisiones médicas cada tanto, o unos simples análisis sanguíneos de vez en cuando, para darse cuenta de cuánto de puramente teóricos o meramente ideales tienen aquellos patrones de la salud sin tacha: cuando no te fallan los triglicéri- 
dos, se altera el colesterol o te sube la bilirrubina. Pero, sostengo, aquel tratado teórico de la salud perfecta seguiría teniendo sentido. Cosa distinta sería que en las facultades de Medicina no se estudiasen y analizasen las enfermedades, sino únicamente un tratado así; que nada más se glosaran las virtudes de la vida saludable o las delicias del cuerpo sano, pero no se adiestrase a los médicos en el diagnóstico y tratamiento de sus defectos, de las enfermedades. Aquel modelo ideal y «contrafáctico» de persona saludable sólo tiene sentido y utilidad si sirve de referencia para, por contraste, detectar, graduar y tratar la enfermedad.

Otra comparación, para acercarnos un poco más a la razón práctica o a la práctica de una cierta razón. Cuando decimos que la democracia sueca es de calidad superior a la democracia venezolana (con perdón de los venezolanos que adoren a su pintoresco presidente), estamos comparando, sí, pero sobre la base de algún patrón normativo de democracia, sepamos explicitarlo en todo su detalle o no. Mas si lo explicitáramos y fuéramos capaces de enumerar los caracteres constitutivos de lo que entendemos por democracia perfecta, se nos podría objetar, con razón, que no se ha plasmado nunca en los hechos ni podrá verse de verdad un sistema tan magnífico; que el ideal, en suma, en ideal se queda, y que tampoco Suecia lo cumple, aunque la pongamos la primera en la clasificación. Mas sería posible replicar dos cosas. Una, que no hemos dicho que Suecia sea la democracia perfecta, sino que, como democracia, es mejor que Colombia (perdón, estábamos con Venezuela). Y dos, que cualquier comparación de este tipo presupone un ideal de referencia, un patrón de medida que es «contrafáctico»: no se da de hecho, pero sirve para medir y escalonar los hechos. Cuando yo opino que la señora $\mathrm{A}$ me amó más que la señora $\mathrm{B}$, no me sirve que me digan que no existe, en los hechos, el amor perfecto; yo ni lo afirmo ni lo pretendo, pero sin presuponer un patrón ideal de amor no puedo diferenciar entre quienes me amaron, si es el caso.

Ésa es la diferencia entre los dos tipos de ciencias o disciplinas que solemos distinguir, las naturales y las sociales o las duras y las blandas: que unas tienen un patrón bastante «real», en cuanto eminentemente empírico, mientras que las otras deben construir patrones ideales con los que medir los peculiares hechos cargados de valoraciones con los que ellas trabajan. No es que en ese terreno que a veces se llama de la razón práctica se esté abocado al idealismo; es que, sin referencias un tanto ideales para medir y clasificar, a lo que estamos condenados es al silencio y la indiferencia, o al egocentrismo más «instrumental»: no sabríamos qué país tiene una democracia mejor; y tendríamos que preguntarnos por qué lo llamamos amor, si propiamente tangible no hay más que el sexo.

En tal sentido, me parece perfectamente admisible y útil todo intento de elaborar patrones ideales de racionalidad argumentativa. No por ser ideales son inútiles, aunque sean irrealizables en su plenitud. Si yo le propongo a mi esposa que vayamos hoy a la playa a Gijón, mi tierra, y ella, no muy convencida, me pregunta que por qué, me pide razones; y si yo le respondo que porque en este momento brilla el sol en el Sur de Australia, mi argumento es, en principio y a falta de mejor aclaración, seriamente defectuoso. Si un juez dice en su sentencia que interpreta tal norma en determinado sentido y que lo hace así porque le da la real gana, que para eso es juez, o porque se le apareció en sueños San Raimundo de Peñafort y le susurró que ésa era su voluntad, estaríamos de acuerdo, nosotros y E. H., que alguna regla «ideal» de la argumentación 
que quiera ser racional se está violando ahí. Creo que la manera de esquivar esa presencia de la racionalidad argumentativa consistiría en sostener que el tipo de racionalidad que rige o impera en la decisión judicial es distinto, no es de carácter argumentativo o «conversacional», y que así debe ser. Pero, en tal caso, deberíamos, primero, decir cuál es o debe ser ese modelo de racionalidad que de los jueces esperamos, y, segundo, tendríamos que pensar que ese juez que ha dado esas justificaciones tan raras que acabamos de ver en el caricaturesco ejemplo, puede estar procediendo de modo perfectamente racional aunque nos ofenda con esas majaderías en su motivación. Pero, entonces, ¿por qué lo obligamos a motivar sus decisiones? Como ha escrito Ó. SARLO, terciando también en la polémica, «si no presuponemos algún ideal de racionalidad, no estaríamos en condiciones de comprender las acciones realizadas, y en especial no estaríamos en condiciones de criticarlas» ${ }^{1}$.

Si rige para los jueces la obligación de motivar sus sentencias, es porque en nuestros sistemas jurídico-políticos no nos conformamos con que la sentencia sea un mero ejercicio de autoridad. Autoridad la tienen también, pero pedimos que los jueces den razones. ¿Sus razones? No, razones admisibles, razones que nos hagan pensar que cualquier persona normal y formada, y decente, también podría haber dictado una sentencia así, si le hubiera tocado hacer de juez en ese caso. El juez debe argumentar para hacernos presentable a nosotros (a las partes, a los especialistas, a cualquiera que pueda entender algo del asunto y examinarlo) esa decisión que es «suya». Si el «sistema» no le deja, de hecho, cumplir honestamente con esa exigencia, será porque el sistema es perverso o indecente, no porque la petición de razones al juez esté fuera de lugar; si es tal o cual juez el que prefiere darnos gato por liebre e ir nada más que a lo suyo, medrando a golpe de sentencia complaciente para los que mandan y reparten (algo sabemos en España de eso), la culpa no será de los ideales de la racionalidad argumentativa, sino de la muy real deshonestidad de ese juez en particular. Por supuesto, si mantemos que todo está perdido y que ni el sistema ni un solo juez se libran de la indecencia constitutiva y definitiva, apaga y vámonos. Más nos valdría dejar la Teoría del Derecho y dedicarnos a criar ovejas o a vender armas, pues de nada servirían ni siquiera las descripciones del realismo más realista: a nadie se convence de que cambie para mejor a base de describirle simplemente cómo es él y sin mostrarle —o imponerle- alguna alternativa debida e ideal.

¿Que los móviles pueden ser unos y las razones presentadas otras y que las segundas ocultan los primeros? No es tan grave. Juzgamos de lo que podemos conocer. Cuando invito a un compañero a cenar en mi casa no quiero que venga en bermudas y camiseta de tirantes, sino aseado y con una indumentaria de cortesía. A lo mejor aparece muy bien vestido y, para sus adentros, se pasa el rato despotricando contra mí y contra los platos que le ofrezco. Pero lo que en su fuero interno piensa y siente no lo sé y, por tanto, no puede importarme. En cambio, si viene sucio, lo veo, lo padezco y tomo su actitud como desconsideración o falta de respeto. Sólo puedo juzgar de lo que

${ }^{1}$ Cuestión distinta, en la que aquí y ahora no podemos entrar, es si el modelo ideal que subyace a teorías como la de ALEXY se deja catalogar como ideal weberiano o si debemos verlo aún más «idealizado», como resultado de la gran influencia de HABERMAS y su idea de que las exigencias de racionalidad argumentativa son, en general, consecuencia de los presupuestos mismos de la acción comunicativa. Creo que las peculiaridades del «ideal» de racionalidad argumentativa constituyen una de las diferencias principales entre los distintos autores de esta corriente, incluso de los que podemos encajar en la teoría estándar. 
me consta, y vivir en la sospecha por lo que pueda estar oculto conduce a la melancolía y a la manía persecutoria. ¿Que estoy presuponiendo unas reglas ideales de cortesía o un modelo puramente teórico de comensal invitado? Sí, pero sin él no podría nadie criticar a quien se le aparezca en casa desnudo, borracho y agresivo, por ejemplo.

Aquí y ahora podemos elaborar un modelo ideal mínimo de argumentación racional. E. H., el mismo E. H., está presuponiendo uno así cuando en sus escritos argumenta con tanta pertinencia y académica contundencia. También lo presupone - y esto es más importante aún- cuando señala los «vicios» en que de hecho suelen incurrir o se ven abocados a incurrir los jueces cuando fallan y argumentan. No hay vicio sin contraste con un modelo de virtud. Si yo critico a un juez por hacer una inferencia errónea, estoy presuponiendo un modelo de inferencia correcta, estoy presuponiendo el juego debido de las reglas de la lógica deductiva. Si reprocho al juez la presencia de alguna falacia en su razonamiento — como E. H. tan abrumadoramente señala—, estoy dando por sentado un modelo de razonamiento correcto, como razonamiento exento de falacias. Es un modelo ideal y, en su idealidad, inalcanzable; pero no puedo dejar de presuponerlo si no quiero renunciar a cualquier ejercicio de la crítica.

2.2. Otra cosa, ciertamente, es el uso que se haga de esos modelos ideales, tan útiles como inevitables. Si en el punto anterior se hacían precisiones críticas a E. H., en éste toca, quizá, concederle algo de razón. Si Hugo Chávez se dedica, en sus breves intervenciones en televisión, a glosar el modelo ideal de democracia con el propósito de persuadir a los venezolanos, con esa sola mención repetitiva de las virtudes del modelo, de que ellos ya viven en la mejor democracia posible y en plena y suprema realización del ideal, nos hallaremos ante una utilización espuria y tramposa de aquel ideal inevitable cuando calificamos y clasificamos democracias reales.

¿Cumplen las teorías estándar de la argumentación jurídica ese inconveniente y hasta ilegítimo papel? No es fácil responder taxativamente, ni haría justicia a la variedad de tales teorías. Así que demos un rodeo. Lo que me parece bien cierto es que hay una diferencia importante entre los inicios de tal tipo de doctrinas y aquello en lo que esas teorías «estándar» han ido a parar. En otras palabras, que, globalmente, prometían más de lo que han dado en cuanto herramienta para el análisis crítico de la argumentación judicial; o que han dado cosas distintas de las que prometían; quién sabe — va en gustos - si mejores o peores, pero distintas. Justifiquemos antes que nada esta afirmación última. Y justifiquemos que también aquí se hable genéricamente de «teoría estándar», a sabiendas de que hay diferencias entre los autores y hasta discusión sobre qué autores encajan bajo esa etiqueta. Pero, al fin y al cabo, es como cuando se decreta la muerte del positivismo jurídico y tampoco se paran algunos a definirlo o a diferenciar entre sus cultivadores. A base de generalizar nos volvemos imprecisos, y cuando precisamos nos hacemos insoportables, por extensos y pesados, y, aun así, siempre nos responden que todavía nos faltó un matiz. De todos modos, al lector que no quiera o no pueda pensar en un conjunto indeterminado de cultivadores de una teoría de la argumentación que es la estándar, le recomiendo que se quede con AlEXY, al que nadie le negará que está en el «núcleo de significado» de la teoría de la argumentación jurídica. Así, además, cualquier otro de esa corriente podrá decir que él no es ALEXY, sino que está en la «zona de penumbra» y que lo que viene no le afecta mayormente. Sin problema. 
Tomemos cualquiera de las doctrinas «estándar» de la argumentación jurídica e intentemos extraer de ella herramientas prácticas para el análisis argumentativo de sentencias, sea en clave descriptiva o sea en clave normativa de modelos de racionalidad. En mi opinión, nos daremos de bruces con dos conclusiones bien sorprendentes. La primera, que apenas nos servirán esas doctrinas para tales propósitos de análisis de materiales prácticos. Cierto que hay algún intento notable, como el de ATIENZA, para construir modelos analíticos para el examen de la estructura argumentativa de la sentencia, de la ilación entre argumentos y entre éstos y el fallo. Pero el enfoque es más descriptivo que normativo, aunque algo pueda tener también de esto último.

La segunda de esas conclusiones es que casi todo lo que de útil se hizo en ese terreno de brindar instrumentos normativos para el análisis práctico se hizo sobre todo en los primeros tiempos o, incluso, entre los precursores de la teoría de la argumentación. Luego la teoría «estándar» se fue por otros derroteros. ¿Qué derroteros serán ésos? Avanzaré mi hipótesis en el subapartado siguiente, pero antes déjenme que concrete un poco más a qué me refiero cuando hablo de análisis práctico de la argumentación desde parámetros normativos de racionalidad.

¿Cómo se hace bien, adecuadamente, un argumento interpretativo de tipo teleológico? Es un mero ejemplo, pero nos basta para lo que se quiere mostrar. ¿Basta señalar que el fin de la norma que se interpreta es tal o cual o es necesario argumentar de determinada manera esa asignación de fin? ¿Y cómo se justifica que la interpretación elegida sirve mejor, por las consecuencias de aplicar la norma con ese sentido, que las interpretaciones alternativas con las que se enfrentaba? ¿Cómo se debe elaborar correctamente un argumento consecuencialista de ese estilo? Si en la teoría «estándar» de la argumentación buscamos indicaciones sobre temas como las exigencias de correcta justificación argumentativa de la aplicación de argumentos, criterios o cánones de interpretación, no vamos a hallar mucho más ni mucho mejor material que el que encontramos en obras de otras orientaciones; poco, en todo caso. Y no digamos si andamos buscando pautas del correcto argumentar sobre los hechos del caso y sobre su prueba y la valoración de ésta. ¿No era a eso a lo que se supone que debería haber ido descendiendo la teoría de la argumentación, una vez sentada la utilidad de los modelos generales de racionalidad argumentativa y asumido que la praxis del Derecho puede ser inserta en ese tipo de racionalidad o, al menos, analizada críticamente desde ahí?

2.3. Lo que, según mi hipótesis, ha pasado es que muchos de los autores que se pueden integrar en esa teoría estándar, empezando por el propio AleXY, han acabado juntando en un mismo paquete su modelo de racionalidad argumentativa de la práctica jurídica decisoria y su idea de que existen pautas morales objetivas (objetivismo) y cognoscibles (cognitivismo) que, bajo la forma que sea (normas jurídicas positivas con especial carga moral, como principios y valores mencionados en las constituciones, o normas extrapositivas, no positivadas, que sin embargo también serían parte del Derecho), ofrecen un referente cierto y objetivo al juez, ya sea porque desde esa amalgama jurídico-moral se presupone única respuesta correcta para cada caso difícil, ya porque en tal conjunción se encuentran por lo menos las reglas que excluyen toda una serie de soluciones positivamente posibles como soluciones incorrectas. 
Sea, pues, más radical la versión iusmoralista o menos, esa alianza de iusmoralismo y teoría de la argumentación desplaza decisivamente el foco. De los casos difíciles ya sólo van a importar destacadamente los casos moralmente difíciles. Cuando la dificultad afecta meramente a las alternativas interpretativas de la norma o a las valoraciones de las pruebas de los hechos, pero no está en juego un valor moral tenido por importante, el tratadista se desentiende bastante, y de ahí esa pérdida de interés por tales cuestiones, que pasan a verse como asuntos menores y cuyo tratamiento no se cultiva con particular esmero. Ahí el juez que argumente como buenamente pueda y, todo lo más, que sea adecuada la justificación interna, que sean correctas las inferencias que realice. Ahí que subsuma en vez de ponderar.

Las consecuencias de ese cambio de rumbo parecen claras: la teoría de la argumentación pierde buena parte de su utilidad para el juez corriente que lidia con casos que no son moralmente dramáticos o trágicos y que se las ve ante todo con dilemas de interpretación o prueba, entre otros problemas eminentemente prácticos y poco emocionantes cuando los valores que haya de por medio no se escriban con mayúscula.

Esa selección de los casos difíciles que en verdad interesan ahora, que son los casos moralmente difíciles nada más (o muy principalmente), hace que la correlación que importe sea la que se da entre racionalidad argumentativa y justicia (o cualquier valor moral a ella reconducible), razón por la cual lo que en la teoría de la argumentación se busca es el respaldo definitivo para la unión de Derecho y moral: a la teoría de la argumentación se le pide que nos indique los modelos, las pautas y el método para la decisión... justa. Aquella tesis de AlEXY sobre el razonamiento jurídico como caso especial del razonamiento práctico general alcanza toda su virtualidad y muestra sus consecuencias, y la distribución de los casos difíciles viene a quedar así: cuando el caso es técnicamente difícil para el juez, por razón de la norma o de los hechos, se subraya la parte especial de la racionalidad y basta con señalar que para eso están la letra de la ley, los precedentes jurisprudenciales y las construcciones de la dogmática; que elija como pueda y que razone con solvencia lógica. Cuando el caso sea moralmente difícil, ganará la moral a esos otros criterios jurídico-positivos y, por ello, especiales.

También tienen su papel, por ejemplo, los cánones interpretativos, entre los que, según ALEXY, hay hasta una cierta jerarquía. Lo que pasa es que todas las prioridades, sean de las normas y su tenor, sean de los precedentes, sean de los criterios de interpretación, son nada más que prioridades o preferencias prima facie. Esto viene a decir que, si no hay problema moral implicado, podemos proceder como perfectos positivistas y hasta asumir una discrecionalidad judicial que no necesita siquiera ir acompañada de gran esfuerzo argumentativo en su ejercicio. Pero si las soluciones propuestas en cualquiera de esas instancias que en principio prevalecen ordenadamente se muestran como soluciones moralmente inaceptables, o si las alternativas decisorias se dan entre normas cuya carga es esencialmente moral, como ocurre con los principios en ALEXY, entonces debemos afirmar la respuesta moralmente correcta (o evitar la lista de las respuestas que moralmente sean incorrectas), y para eso, para justificar esa corrección de las elecciones que son morales o de razón práctica general, tiene que servirnos un método argumentativo movido por esa idea muy fuerte y ambiciosa de racionalidad argumentativa. 
Naturalmente, desde el instante en que la racionalidad argumentativa se pone al servicio de la calidad moral de las decisiones judiciales y siempre que, obviamente, no se quiera que esa argumentación opere en el vacío o sea nada más que puro subterfugio o disfraz de la arbitrariedad, se tiene que estar presuponiendo algún tipo o grado de objetivismo moral y de cognitivismo. En autores de la relevancia de AlEXY estaban ambos, pero se mostraban con cierta timidez, había que captarlos entre líneas. En otros ha sido más clara la toma de conciencia de esa implicación o más honesta la exposición de los presupuestos, y se cierra más coherente y expresamente esa alianza entre iusmoralismo y teoría de la argumentación. Me parece que este debate, aquí, entre E. H. y M. A. no se entiende cabalmente ni se capta siquiera la razón de tanta pasión si no se toma conciencia de que están discutiendo, en el fondo, por esto y sobre esto, lo mencionen más o lo mencionen menos y aunque se vayan a ratos por los cerros de Úbeda o nos despisten con variados pormenores sobre la obra - muy importante- de cada uno.

3. ¿Será buena o mala, positiva o negativa, esa deriva de la teoría estándar de la argumentación? Cada cual la juzgará desde los parámetros de la iusfilosofía a la que se adscriba. Para el realismo jurídico duro de E. H., después del primer PERELMAN no va quedando en dicha teoría apenas nada más que quimera especulativa y una enésima contribución al disfraz de la muy prosaica práctica jurídica y judicial con galas que no son de su penosa talla, un instrumento más para ocultar, bajo los ropajes ideales de una razón muy práctica, la práctica de cada día, que poco sabe de la razón y sus deliberaciones y mucho de cierta fuerza normativa de lo fáctico.

Para la concepción antipositivista de M. A., no podemos conformarnos con diagnosticar las penas y penurias de la práctica real y tenemos que tratar de orientarla hacia una mejor y una más plena consumación de los presupuestos del Estado constitucional que, si mal no entiendo - y creo que no- - son presupuestos morales antes que nada y yacen en alguna esfera del ser (objetivismo) esperando para ser descubiertos por la razón (cognitivismo) cuando haya un litigio que los toque de cerca.

Para este que suscribe, que se dice positivista, pero que transita por parajes más cercanos a un cierto normativismo (espero que sin síndrome, o con síndrome leve) que al agreste realismo - sin quitar su importancia al conocimiento de los hechos y sus causalidades, pero convencido de que metodológicamente no debemos confundir hechos y normas, descripciones de procesos empíricos con modelos normativos-, la señalada evolución, de ser cierta, tiene dos vertientes, una de las cuales me resulta un tanto indiferente, mientras que la otra la lamento un tanto.

Por un lado, no tiene especial emoción ni es acicate para nuevos debates el que el programa más o menos oculto de buena o alguna parte de esa tal teoría estándar acabara siendo la enésima reedición del iusmoralismo y una nueva razón para seguir declarando la muerte y eterna condena de cuantos positivismos hayan sido o sean, a fin de que cuando uno tenga un pleito pueda invocar la norma positiva en lo que le convenga y la moral cuando ésta le dé más ventajas, pero con la tranquila conciencia de que, sea lo uno o lo otro lo que uno miente, será Derecho eso que en cada ocasión mienta uno.

Pero, por otro lado, sí lamento que los empeños teóricos de tantos autores tan capaces se hayan concentrado principalmente (con las excepciones de rigor, pocas) en 
la renovación de los planteamientos que otrora fueron propios del iusnaturalismo y de rancias teorías materiales de los valores. No es, por supuesto que no, que los iusmoralistas argumentativos sean iusnaturalistas o aplicados discípulos de un SCHELER, por ejemplo, sino que toman el testigo para renovar más sutilmente el viejo afán de moralizar el Derecho al poner a los jueces a bailar al son de una ética que todos dicen ahora que es la de la Constitución, pero cuyos contenidos no coinciden en (casi) ninguno. No lamento ese paso porque hagan tal cosa, sino por lo que han dejado de hacer por lo común: análisis del discurso jurídico y de la decisión judicial ordinaria, en los casos ordinariamente difíciles y no en esos otros en los que pareciera que pleitean ángeles y demonios y no ciudadanos del montón. Y no es que sea incompatible hacer lo uno y lo otro, pero a quién puede interesarle meter tiempo al despiece analítico de un argumento sistemático o del argumento sobre la prueba pericial, cuando puede uno dedicarse a pontificar sobre el bien y el mal y a indicarles a los jueces cómo deben decidir tal o cuál caso, y no meramente cómo han de argumentar su discrecional decisión cuando las normas y las cosas están dudosas.

4. Y fin. No sólo es probable que sea erróneo cada uno de los diagnósticos recién expuestos sobre (el trasfondo de) las tesis de mis amigos E. HABA y M. ATIENZA y sobre la evolución y estado de una teoría de la argumentación estándar que, al parecer, casi nadie sabe exactamente qué es ni quién la hizo - y sería inmodestia que me considerase yo la excepción-. Es que, además, por razones de espacio, tiempo y carácter, he tenido que incurrir yo mismo en cuantas falacias mis dos queridos colegas han venido manejando, y hasta es probable que, diestros como son en el lanzamiento de falacia, me imputen con buenos argumentos unas cuantas más. Pero, como tengo entendido que este debate ha de seguir y que habrá nuevos asaltos y sobresaltos, me comprometo a deshacerlas todas a base de pergeñar otras nuevas y más rotundas, como es habitual en el gremio. 